\title{
Budget Impact Analysis of a Renal Point-of-Care Test in Dutch Community Pharmacies to Prevent Antibiotic-Related Hospitalizations
}

\author{
Judith J. Gout-Zwart ${ }^{1,2}$ (D) Erien H. J. Olde Hengel ${ }^{3} \cdot$ Petra Hoogland ${ }^{4} \cdot$ Maarten J. Postma $^{3,5,6}$
}

Published online: 3 September 2018

(c) The Author(s) 2018

\begin{abstract}
Objectives Medication errors that lead to adverse drug reactions are a key cause of unintentional patient harm and subsequent economic burden. To prevent this, measurement of renal function could be considered. The aim of this study was to determine the budget impact of obtaining and evaluating renal function in community pharmacies in the Netherlands to prevent antibiotic-related hospitalizations.

Methods A decision model was built to simulate the process of antibiotic prescriptions in community pharmacies with and without the use of a point-of-care test (PoCT) in patients aged 65 years and older. By using a PoCT, the number of patients with renal function values available increases, leading to the possibility of dose adjustment when necessary. In turn, this might avoid hospitalizations. For this study, real-life patient data were used from 351 community pharmacies. Direct costs of renal function screening, antibiotic treatments, and medical care due to antibiotic-related hospitalization were included. Results The budget impact analysis showed annual cost-savings of $€ 86$ per patient through the availability of renal function values in Dutch community pharmacies. Savings were mostly due to avoided hospitalizations.

Conclusion Obtaining and evaluating renal function in community pharmacies by point of care tests is expected to be costsaving in the Netherlands.
\end{abstract}

Electronic supplementary material The online version of this article (https://doi.org/10.1007/s40258-018-0426-2) contains supplementary material, which is available to authorized users.

Judith J. Gout-Zwart

judith@ascacademics.com

1 Asc Academics, Westerhaven 13, 9718 AW Groningen, The Netherlands

2 Department of Nephrology, University of Groningen, University Medical Center Groningen (UMCG), Hanzeplein 1, 9713 GZ Groningen, The Netherlands

3 Groningen Research Institute of Pharmacy, PharmacoTherapy, Epidemiology and Economics, University of Groningen, Antonius Deusinglaan 1, 9713 AV Groningen, The Netherlands

4 Service Apotheek Nederland, De Weegschaal 14, $5215 \mathrm{MN}$ 's-Hertogenbosch, The Netherlands

5 Institute for Science in Healthy Aging and healthcaRE (SHARE), University of Groningen, University Medical Center Groningen (UMCG), Groningen, The Netherlands

6 Department of Health Sciences, University of Groningen, University Medical Center Groningen (UMCG), Hanzeplein 1, 9713 GZ Groningen, The Netherlands

\section{Key Points for Decision-Makers}

The use of a renal point-of-care test could reduce the number of adverse event-related hospitalizations from antibiotics.

Using a renal point-of-care test in community pharmacies might be a cost-saving alternative to the standard of care.

\section{Introduction}

Medication errors and adverse drug events are important causes of unintentional patient harm and may lead to hospitalizations [1]. Additionally, the incidence of renal impairment is increasing, potentially caused by the aging population and the worldwide increasing incidence of hypertension and diabetes mellitus [2]. A decreased renal function is one of the risk factors for drug-related hospital admissions. In fact, this causes $10 \%$ of all medication-related 
hospitalizations. Adjustment of the dosage, dose interval, or drug substitution could prevent these hospitalizations [3].

In case of an impaired kidney function, medication monitoring is often crucial, thus the availability of an up-to-date renal function value, as well as a sufficient medication monitoring system, is important. More awareness by general practitioners (GPs) and specialists might help to reduce adverse drug events, as might interventions from community pharmacists such as renal function-based dose adjustments or drug substitutions $[4,5]$.

In routine clinical care, renal function is estimated (estimated glomerular filtration rate, eGFR) from a serum creatinine value, using a formula that also includes age, sex, and race as variables [6]. Unfortunately, eGFR values are often absent in community pharmacies, mostly due to the absence of a patient's permission to exchange laboratory values between healthcare professionals [7]. Additionally, an overload of medication-monitoring signals leads to alert fatigue. To increase the relevance of medication-monitoring signals in case of impaired renal function, medical-pharmaceutical decision rules (MFBs) are developed, which are linked to the patient's age [4]. Furthermore, it is important to immediately start with antibiotics to prevent exacerbations and the spreading of bacteria in case of an infection. When a recent eGFR value is unavailable, renal function measurement should be initiated by the prescriber, blood should be drawn at a diagnostic center, and serum creatinine analyzed in a lab, which may take up to several days $[3,4]$.

In addition to the burden for the patient, the inappropriate prescribing of antibiotics in case of unknown impaired renal function can laed to high medical costs. The total direct medical costs for preventable adverse events were $€ 161$ million in 2004 in the Netherlands [8]. The proportion of antibiotic-related adverse events due to unknown renal function is still unknown.

The use of a point-of-care test (PoCT) might increase the availability of renal functions in community pharmacies by motivating prescribers to share these values with pharmacists, as well as by using the PoCT itself. A PoCT is a device that provides medical diagnostic testing near the point-ofcare, which is the time and place of patient care. In 2015 a PoCT for renal function measurement was introduced in the Netherlands in 336 community pharmacies. The importance and relevance of better medication monitoring in community pharmacies in patients with renal impairment is described in a previously published study by Heringa et al. [4, 9].

The aim of this study was to carry out a budget impact analysis of obtaining and evaluating eGFR values in patients presenting themselves with antibiotic prescriptions in community pharmacies in the Netherlands, using a renal PoCT.

\section{Methods}

\subsection{Model Design}

A decision model was built in Microsoft Excel 2016 to assess the budget impact on healthcare costs by increasing the number of available renal functions by using the StatSensor ${ }^{\circledR}$ Point of Care Creatinine and eGFR Analyzer $[10,11]$. This PoCT is a handheld, miniature biosensor for wholeblood creatinine testing and provides an assessment of renal function by finger stick capillary blood sampling, which can be executed in the community pharmacy [12]. The standard of care $(\mathrm{SoC})$ was simulated by incorporating medication monitoring with impaired renal function in community pharmacies. Currently, prescribers should initiate the gathering of renal functions in patients who are at risk of renal impairment. Community pharmacies can obtain these renal function values from the prescriber or from the LSP, which is a secure network for sharing medical information electronically [13]. When the necessary information is unavailable, obtaining a renal function might take up to several days, while antibiotic treatment has to start immediately. The pharmacist will then deliver the antibiotic without evaluation of renal function values, which is a risk that might lead to adverse events and hospitalizations. In this model, the SoC was compared to the introduction of MFBs and the PoCT (Appendix 1, Figs. 2 and 3). An MFB generates an alert when dose adjustment is advised, based on a registered impaired renal function or when renal function information is lacking for people over 70 years old, with a prescription for a drug for which this information is considered important [4]. The goal of introducing the MFBs and PoCT is to increase the availability of renal function values in community pharmacies, with the possibility of obtaining such values when urgently needed. ISPOR budget impact analysis principles of good practice were used to ensure good methodology. The model was validated using the Assessment of the Validation Status of Health-Economic decision models (AdViSHE) tool [14]. Renal impairment is categorized from normal to end-stage renal disease based on eGFR following advice of the European Medicines Agency (EMA, Table 1) [15].

Table 1 Categorization of renal impairment by eGFR value

\begin{tabular}{ll}
\hline eGFR value $\left(\mathrm{ml} / \mathrm{min} / 1.73 \mathrm{~m}^{2}\right)$ & Renal impairment category \\
\hline$>80$ & Normal \\
$50-80$ & Mild \\
$30-50$ & Moderate \\
$10-30$ & Severe \\
$<10$ & End-stage renal disease \\
\hline
\end{tabular}


The antibiotics considered were amoxicillin/clavulanic acid, ciprofloxacin, clarithromycin, cotrimoxazole, nitrofurantoin, norfloxacin, and trimethoprim, because these require an intervention in case of decreased renal function [4]. Dose adaptations were based on The Royal Dutch Pharmacists Association guidelines, which are also available from the National Health Care Institute [16, 17]. To evaluate the budget impact, the model was populated with 1,000,000 patients.

\subsection{Study Population and Time Horizon}

The anonymous patient data included 117,190 patients from 351 Service Apotheek pharmacies in the Netherlands. Patients who received drugs other than antibiotics and patients without a clear prescription handling pathway were excluded from the analysis. This analysis focuses on antibiotics since a direct start of therapy is indicated, as opposed to the other drugs, where a few days delay might be acceptable. Ultimately, 88,514 patients were included (Fig. 1). The dataset contained information regarding patients' year of birth, gender, prescribed medication, (handling of) MFB signals, the use of the PoCT, and eGFR values.
This analysis was performed from the healthcare payers' perspective. In line with the budgeting process of the Dutch health system, as well as the ISPOR guidelines for budget impact analyses, a time horizon of 1 year was chosen. As the PoCT was introduced in 2015, we modelled from the 1 January until the 31 December 2016, to avoid potential startup-phase data gathering problems in the Service Apotheek project. Among other things, their project aimed to investigate the frequency and management of drug therapy alerts about drug use in patients with (potential) renal impairment as well as the contribution of PoCT in community pharmacies to the availability renal function information [4].

\subsection{PoCT}

The patient dataset reflecting the included study population was the main source for estimating transition probabilities in the decision model (Appendix 2, Table 7). Patient characteristics are displayed in Table 2 [9]. When patients had more than one prescription of interest in the studied year (and therefore were in the dataset more than once), we only used their information if there was a $>13$-month interval between visits. If this was less than 13 months, we used the first renal function value.

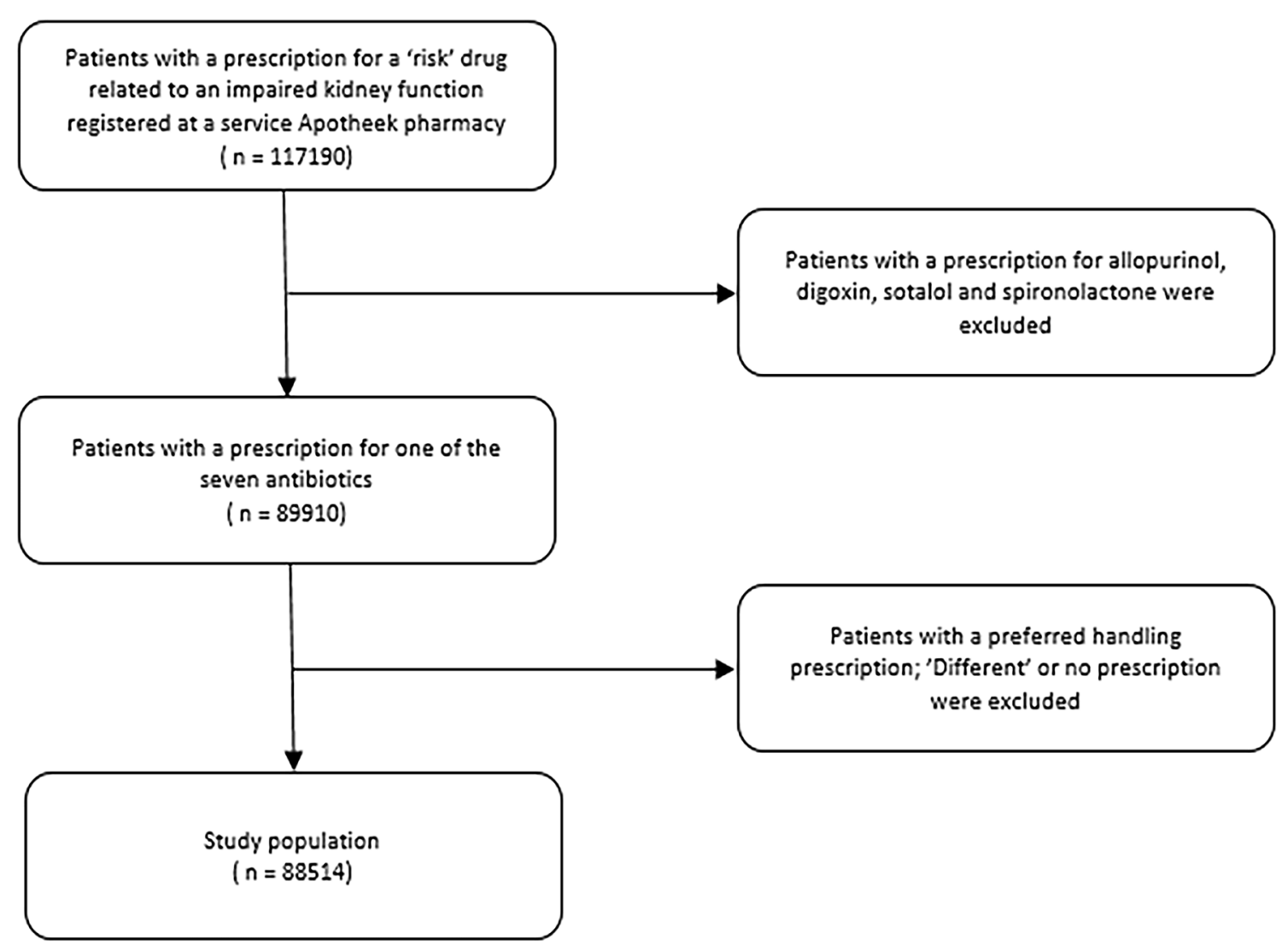

Fig. 1 Inclusion and exclusion of patients from the Service Apotheek dataset for the budget impact analysis 
Table 2 Patient characteristics of the Service Apotheek dataset from 351 community pharmacies

\begin{tabular}{lr}
\hline Characteristics & \\
\hline $\begin{array}{l}\text { Age in years, mean } \\
\quad \text { (median) }\end{array}$ & $80(80)$ \\
Male $(n)$ & \\
Female $(n)$ & 24,376 \\
Unknown $(n)$ & 62,043 \\
\hline
\end{tabular}

Table 3 Sensitivity and specificity of the StatSensor creatinine point-of-care test

\begin{tabular}{lr}
$\begin{array}{l}\text { StatSensor creatinine } \\
\text { point-of-care test }\end{array}$ & \multicolumn{1}{c}{$\%$} \\
\hline Sensitivity & 96.30 \\
False negative & 3.70 \\
Specificity & 100.00 \\
False positive & 0.00
\end{tabular}

From the confidential validation report, Table 3 illustrates the test characteristics of the StatSensor Creatinine PoCT at an eGFR $<30$, since intervention is only required for these patients according to The Royal Dutch Pharmacists Association guidelines [16]. The dataset showed $4.71 \%$ of all patients have an eGFR $<30$. The percentage of renal functions measured by the PoCT with eGFR $<30$ was $0.76 \%$. Hospitalization caused by adverse events of antibiotic treatment was assumed to be $0.1 \%$ from the number of severe adverse events [16].

\subsection{Costs}

Costs are shown in Table 4 with respective references [18, 19]. We assumed one PoCT per pharmacy was sufficient for at least the timeframe of 1 year, at a price of $€ 250$. Every measurement requires a new strip for blood sampling. Currently the use of a PoCT is not reimbursed, so either the pharmacist or the patient must pay for the use of the PoCT. The SoC costs resulted from antibiotic treatment costs and medical care from antibiotic-related hospitalizations due to an unknown impaired renal function. The specific costs of adverse events due to inappropriate dose adjustment following renal impairment are unknown. Therefore these costs were derived from the Dutch Cost Manual, which describes the average costs per hospital day, the average length of stay, and the costs of an emergency room (ER) and intensive care unit (ICU) visit [19].

The costs of the new situation resulted from costs of renal function measurement using the PoCT, treatment with antibiotics, and medication-related hospitalization due to an impaired renal function. The impact of the different assumptions in the model was assessed in a univariate sensitivity analyses for the initial (base-case) analysis. All costs were inflated to the year 2016 for the purpose of consistency and using the appropriate deflators [20]. The costs for the PoCT apparatus and strips were based on information from Service Apotheek and Menarini Diagnostics, the Netherlands [21, 22].

\subsection{Scenario Analyses}

Scenario analyses were conducted to evaluate the budget impact at different levels of increased availability of renal function values. Since the baseline value was $46.07 \%$ renal function unavailability in all subjects, the percentage of values provided by the prescriber/laboratory and from the PoCT was increased by 5,10 , and $20 \%$.
Table 4 Costs included in the budget impact analysis, 2016 price levels

\begin{tabular}{llll}
\hline & Costs $^{\mathrm{a}}$ & $\begin{array}{l}\text { Intervention with creatinine clearance } \\
10-30 \mathrm{ml} / \mathrm{min}\end{array}$ & Costs $^{\mathrm{a}}$ \\
\hline $\begin{array}{l}\text { Amoxicillin/clavulanic acid } \\
\text { 500/125 mg 3 dd }\end{array}$ & $€ 36.90[18]$ & Change dose to 875/125 mg 2 dd & $€ 35.23[18]$ \\
Ciprofloxacin 500 mg 2 dd & $€ 35.20[18]$ & Change dose to 500 mg 1 dd & $€ 34.89[18]$ \\
Clarithromycin 250 mg 2 dd & $€ 36.92[18]$ & $50 \%$ of dose & $€ 34.37[18]$ \\
Cotrimoxazole 960 mg 2 dd & $€ 34.71[18]$ & $50 \%$ of dose & $€ 33.52[18]$ \\
Nitrofurantoin 50 mg 4 dd & $€ 33.73[18]$ & Change to trimethoprim & $€ 35.60[18]$ \\
Norfloxacin 400 mg 2 dd & $€ 38.21[18]$ & Change dose to 400 mg 1 dd & $€ 35.60[18]$ \\
Trimethoprim 300 mg 1 dd & $€ 33.52[18]$ & 3 days normal dose, then 50\% of dose & $€ 33.52[18]$ \\
Hospitalization & $€ 5347.52[19]$ & & \\
PoCT per strip [3] & $€ 5.40$ & & \\
Statsensor Creatinine & $€ 250$ & & \\
\hline
\end{tabular}

$d d$ daily dosage, PoCT point-of-care test

${ }^{a}$ Costs for all antibiotic prescriptions include a consultation with the prescriber (assumed to be the general practitioner, €33 [19]) 


\section{Results}

\subsection{Budget Impact Analysis}

Our analysis shows that an increased availability of renal function information in community pharmacies through the use of a PoCT is potentially cost-saving. Annual hospitalization costs due to renal function-related adverse events were $€ 230.108 .680$. The total annual costs per patient were $€ 264.20$ and $€ 178.12$ for the SoC and the PoCT, respectively, leading to cost savings of $€ 86.08$.

In 2016 the Netherlands counted 1994 community pharmacies, meaning the database we used included information of $17.6 \%$ of all community pharmacies [23]. Considering the database consisted of 88,514 patients of interest, this leads to an annual number of 502.760 patients with antibiotic prescriptions, of which 231,622 would have an unknown eGFR. These data imply that availability of information on renal function in all relevant cases could add up to cost savings of $€ 19,938,021$ per year in the Netherlands.

\subsection{Scenario Analyses}

Scenario analyses show that savings might add up to more than $€ 207$ per patient if the introduction of a creatinine PoCT would lead to availability of almost all necessary renal functions (Table 5).

In the univariate sensitivity analysis, the parameters were varied over a range of $75-125 \%$ of the deterministic values from Table 4 . We excluded the percentage of adverse events (5.7\%) from the univariate sensitivity analysis, since this only has a small effect on the outcome. The univariate sensitivity analysis shows that hospitalization costs, PoCT costs, and cost of dose per consultation with the prescriber have the most influence on the outcomes of the analysis (Table 6).

\section{Discussion}

To our knowledge, this is the first economic analysis studying the obtainment and evaluation of renal function values in community pharmacies, using a PoCT. The results of this analysis show that obtaining eGFR values by using the PoCT
Table 6 Univariate sensitivity analysis

\begin{tabular}{|c|c|c|}
\hline & \multicolumn{2}{|c|}{ Total costs per patient } \\
\hline & $\begin{array}{l}75 \% \text { of } \\
\text { deterministic } \\
\text { value }\end{array}$ & $\begin{array}{l}125 \% \text { of } \\
\text { deterministic } \\
\text { value }\end{array}$ \\
\hline $\begin{array}{l}\text { PoCT apparatus costs ( } € 187.50 \text {; } \\
\quad € 312.50)\end{array}$ & $-€ 86.51$ & $-€ 85.65$ \\
\hline PoCT strip costs (€4.05; €6.75) & $-€ 86.16$ & $-€ 86.00$ \\
\hline $\begin{array}{l}\text { Hospitalization costs }(€ 4010.64 \text {; } \\
€ 6684.40)\end{array}$ & $-€ 64.03$ & $-€ 108.12$ \\
\hline $\begin{array}{l}\text { Costs of dose consultation with pre- } \\
\text { scriber }(€ 26.99 ; € 44.99)\end{array}$ & $-€ 86.14$ & $-€ 86.01$ \\
\hline
\end{tabular}

in Dutch pharmacies might be a cost-saving alternative to the current practice.

The use of real patients' data in this study increases the reliability of the analysis, as the data contained complete information on the process of antibiotic prescriptions in the included pharmacies, with all corresponding registered eGFR values. Data from 88,514 patients was included in the study, which is a large and relevant study population.

If this study took quality of life of patients into account, we postulate that patients would generally feel better due to averted hospitalizations, as this would outweigh the burden of the PoCT. Additionally, the PoCT provides a quick and accurate result. This is why pharmacists might be likely to implement the use of a renal PoCT to improve pharmaceutical care [24].

As with all economic analyses, this study has some limitations. Firstly, several assumptions had to be made in order to complete the model. The most important ones were used in the SoC modelling (renal function provided by the GP/ laboratory and the amount of patients in this population with an eGFR <30). For future research, assumptions could be validated with patient-level data to increase the robustness of the model.

No specific number of antibiotic-related adverse events due to impaired renal function was found, so general drugrelated adverse events data was used [25]. Since this value includes all drugs that might cause side effects due to a lack of monitoring in patients with impaired renal function, the percentage of antibiotic-related adverse events is likely to be different.
Table 5 Scenario analyses: cost savings by increasing the availability of eGFR values compared to the current situation

\begin{tabular}{llll}
\hline & $\begin{array}{l}5 \% \text { increased } \\
\text { availability }\end{array}$ & $\begin{array}{l}10 \% \text { increased } \\
\text { availability }\end{array}$ & $\begin{array}{l}20 \% \\
\text { increased } \\
\text { availability }\end{array}$ \\
\hline Renal function provided by GP/laboratory & $-€ 101.31$ & $-€ 116.54$ & $-€ 147.01$ \\
Renal function provided by PoCT & $-€ 101.04$ & $-€ 116.01$ & $-€ 145.94$ \\
Renal function provided by GP/laboratory and PoCT & $-€ 116.28$ & $-€ 146.48$ & $-€ 206.87$ \\
\hline
\end{tabular}


When a patient has a PoCT result that indicates renal failure, the outcome should be confirmed by a laboratory test initiated by the general practitioner. We did not take these cost into account because this is unrelated to antibiotic delivery and treatment. For the same reason we did not include costs that come from this result in the future, such as treatment. Had we included confirmation costs, the outcome would potentially be less favorable, but could still be cost-saving.

To conclude, our findings show that the availability of information on renal function in community pharmacies may be a cost-saving alternative to the SoC. More research is needed, to evaluate the impact of increased information on renal function for other drug categories, where the impact might be bigger than for antibiotics. Additionally more research should be conducted to evaluate the cost of the inappropriate prescription of medication.

Acknowledgements We thank health-economist Evgeni Dvortsin and nephrologist Prof. Dr. Ron Gansevoort for their input and Sipke Visser for helping us generate information from the dataset.

Author Contributions JG and EO designed the model and the computational framework and analysed the data. EO performed the calculations.
JG and EO wrote the manuscript with input from all contributors. JG and MP conceived the study and were in charge of overall direction and planning.

\section{Compliance with Ethical Standards}

This study was funded by NOVA Biomedical and Menarini Diagnostics. Data were provided by Service Apotheek. JG, EO, and PH have no conflicts of interest to declare. MP received grants from various pharmaceutical companies, all fully unrelated to this research.

Data Availability Statement The model underpinning this research is available as a supplementary file.

Open Access This article is distributed under the terms of the Creative Commons Attribution-NonCommercial 4.0 International License (http://creativecommons.org/licenses/by-nc/4.0/), which permits any noncommercial use, distribution, and reproduction in any medium, provided you give appropriate credit to the original author(s) and the source, provide a link to the Creative Commons license, and indicate if changes were made.

\section{Appendix 1: Decision model}

See Figs. 2 and 3.

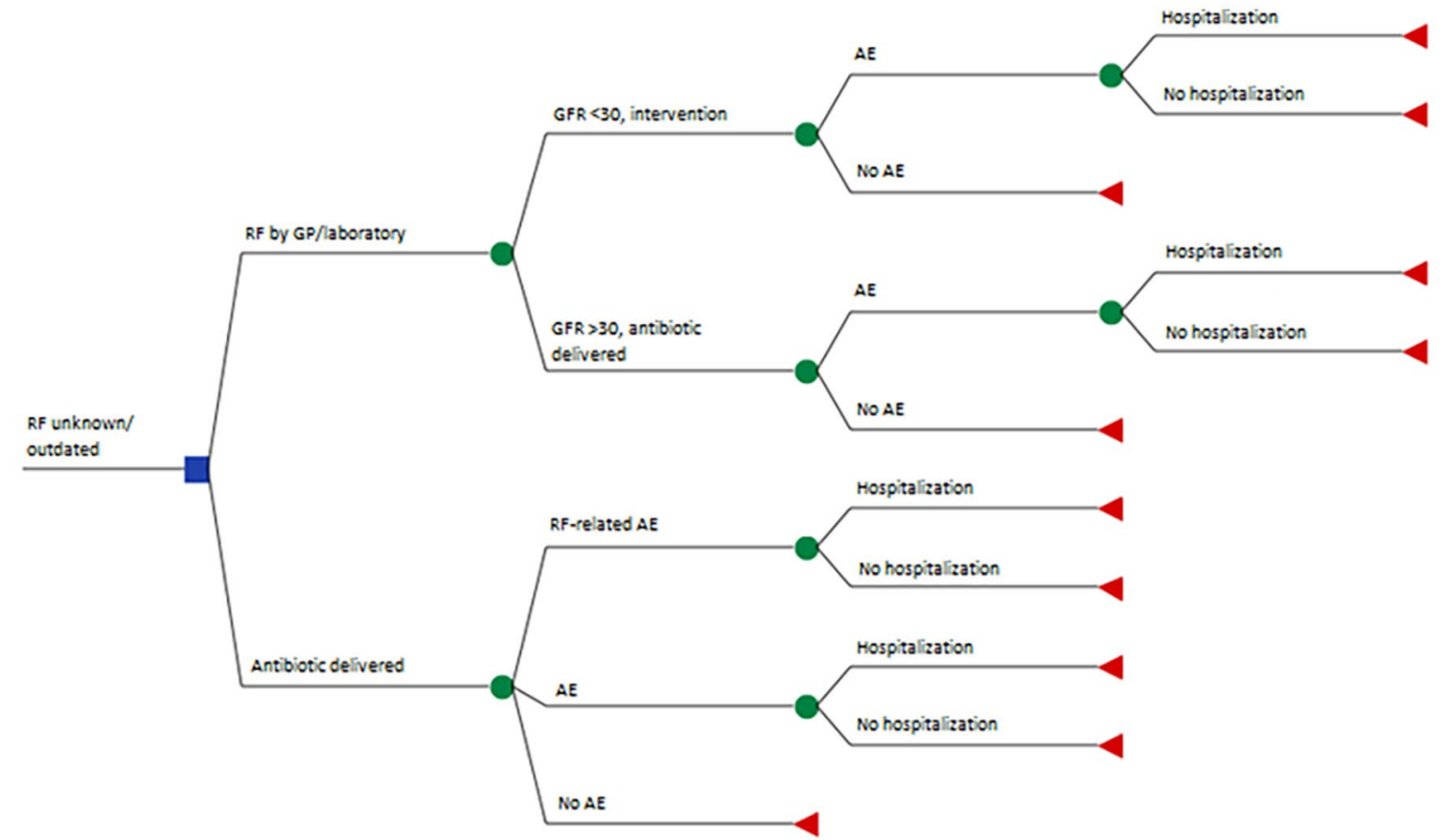

Fig. 2 Decision model 'Standard of Care'. $A E$ adverse events, $G F R$ glomerular filtration rate, $G P$ general practitioner, $R F$ renal function 


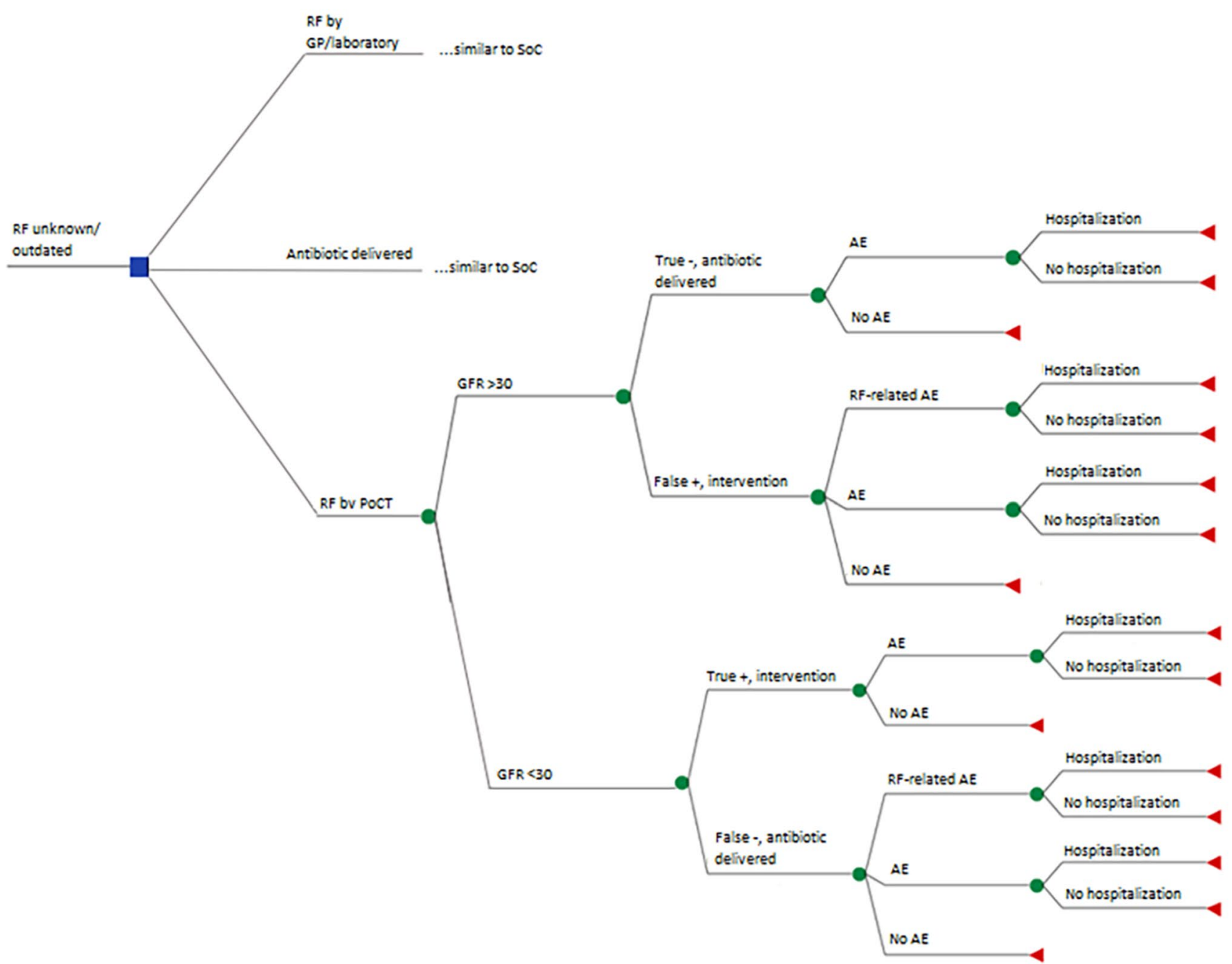

Fig. 3 Decision model 'PoCT'. $A E$ adverse events, GFR glomerular filtration rate, $G P$ general practitioner, $P o C T$ point of care test, $R F$ renal function 


\section{Appendix 2: Transition probabilities}

See Table 7.

Table 7 Transition probabilities used in the decision model

\begin{tabular}{|c|c|c|c|c|}
\hline & $\mathrm{SoC}$ & Reference & PoCT & Reference \\
\hline RF by GP/laboratory & 0.25 & Assumption & 0.481 & Dataset \\
\hline GFR $<30$, intervention & 0.047 & Dataset & 0.047 & Dataset \\
\hline Change dose to $875 / 125 \mathrm{mg} 2 \mathrm{dd}$ & 0.122 & Dataset & 0.122 & Dataset \\
\hline $50 \%$ of dose & 0.118 & Dataset & 0.118 & Dataset \\
\hline 3 days normal dose, then $50 \%$ of dose & 0.045 & Dataset & 0.045 & Dataset \\
\hline Change to trimethoprim & 0.062 & Dataset & 0.062 & Dataset \\
\hline Dose consultation & 0.653 & Dataset & 0.653 & Dataset \\
\hline GFR $>30$, antibiotic delivered & 0.953 & Dataset & 0.953 & Dataset \\
\hline Amoxicillin/clavulanic acid & 0.178 & Dataset & 0.178 & Dataset \\
\hline Ciprofloxacin & 0.122 & Dataset & 0.122 & Dataset \\
\hline Clarithromycin & 0.036 & Dataset & 0.036 & Dataset \\
\hline Cotrimoxazole & 0.041 & Dataset & 0.041 & Dataset \\
\hline Nitrofurantoin & 0.523 & Dataset & 0.523 & Dataset \\
\hline Norfloxacine & 0.021 & Dataset & 0.021 & Dataset \\
\hline Trimethoprim & 0.079 & Dataset & 0.079 & Dataset \\
\hline $\mathrm{AE}$ & 0.111 & [16] & 0.111 & {$[16]$} \\
\hline Hospitalization & 0.001 & {$[16]$} & 0.001 & [16] \\
\hline No hospitalization & 0.999 & [16] & 0.999 & {$[16]$} \\
\hline RF-related AE & 0.057 & {$[25]$} & 0.057 & {$[25]$} \\
\hline RF-related AE, hospitalization & 1.000 & Assumption & 1.000 & Assumption \\
\hline RF-related AE, no hospitalization & 0.000 & Assumption & 0.000 & Assumption \\
\hline GFR $<30 \rightarrow$ No AE & 0.889 & [16] & 0.889 & {$[16]$} \\
\hline GFR $>30 \rightarrow$ No AE & 0.889 & [16] & 0.889 & [16] \\
\hline Antibiotic delivered, RF unknown & 0.750 & Assumption & 0.461 & Dataset \\
\hline No AE & 0.832 & Assumption & 0.832 & 1 - “(RF-related $) A E ”$ \\
\hline RF by PoCT & & & 0.058 & Dataset \\
\hline GFR $>30$ & & & 0.992 & Dataset \\
\hline True - , antibiotic delivered & & & 1.000 & PoCT validation report \\
\hline False,$+ \mathrm{AE}$ & & & 0.000 & PoCT validation report \\
\hline GFR $<30$ & & & 0.008 & Dataset \\
\hline GFR $<30$, False - , antibiotic delivered & & & 0.037 & PoCT validation report \\
\hline
\end{tabular}

$A E$ adverse events, $G F R$ glomerular filtration rate, $P o C T$ point-of-care test, $R F$ renal function, $S o C$ standard of care

\section{References}

1. Leendertse AJ, Egberts ACG, Stoker LJ, van den Bemt PML. Frequency of and risk factors for preventable medicationrelated hospital admissions in the Netherlands. Arch Intern Med. 2008;168(17):1890-6. https://doi.org/10.1016/S0084 $-3873(09) 79549-5$.

2. Verbeeck RK, Musuamba FT. Pharmacokinetics and dosage adjustment in patients with renal dysfunction. Eur J Clin Pharmacol. 2009;65(8):757-73. https://doi.org/10.1007/s0022 8-009-0678-8.

3. Projectplan Nierfunctieproject 2015-2016. Service Apotheken. 2016.
4. Heringa M, van de Steeg-van Gompel CH, Bouvy ML. MedischFarmaceutische Beslisregels En Nierfunctiemeting in de Openbare Apotheek: Wat Levert Het Op? Netherlands; 2017. Available at https://www.knmp.nl/professie/wetenschap/nederlands-platf orm-voor-farmaceutisch-onderzoek/medisch-farmaceutische-besli sregels-en-nierfunctiemeting-in-de-openbare-apotheek-wat-lever t-het-op.

5. Joosten H, Drion I, Boogerd KJ, van der Pijl EV, Slingerland RJ, Slaets JPJ, et al. Optimising drug prescribing and dispensing in subjects at risk for drug errors due to renal impairment: improving drug safety in primary healthcare by low eGFR alerts. BMJ Open. 2013;3(1):e002068. https://doi.org/10.1136/bmjopen-2012-00206 8. 
6. Levey AS, Stevens LA, Schmid CH, Zhang YL, Castro AF 3rd, Feldman HIA, et al. A new equation to estimate glomerular filtration rate. Ann Intern Med. 2009;150(9):604-12.

7. Koster ES, Philbert D, Noordam M, Winters NA, Blom L, Bouvy ML. Availability of information on renal function in Dutch community pharmacies. Int J Clin Pharm. 2016;38(4):797-801. https ://doi.org/10.1007/s11096-016-0332-3.

8. Van Hilten O MA. Figures in health and healthcare 2007. Voorburg/Heerlen CBS, 2007.

9. Heringa M, Floor-Schreudering A, De Smet PAGM, Bouvy ML. Clinical decision support and optional point of care testing of renal function for safe use of antibiotics in elderly patients: a retrospective study in community pharmacy practice. Drugs Aging. 2017;34(11):851-8. https://doi.org/10.1007/s40266-017-0497-z.

10. Mauskopf JA, Sullivan SD, Annemans L, Caro J, Mullins CD, Nuijten M, et al. Principles of good practice for budget impact analysis: report of the ISPOR Task Force on good research practices-budget impact analysis. Value Health. 2007;10(5):336-47. https://doi.org/10.1111/j.1524-4733.2007.00187.x.

11. Sullivan SD, Mauskopf JA, Augustovski F, Jaime Caro J, Lee KM, Minchin M, et al. Budget impact analysis-principles of good practice: report of the ISPOR 2012 budget impact analysis good practice II task force. Value Health. 2014;17(1):5-14. https://doi. org/10.1016/j.jval.2013.08.2291.

12. Nova Biomedical: StatSensor ${ }^{\circledR}$ Point-of-Care Creatinine and eGFR Analyzers. Available at http://www.novabio.us/statstripcreatinine/. Accessed July 2, 2018.

13. VZVZ-Over het LSP. Available at https://www.vZvZ.nl/over-het1sp. Accessed July 2, 2018.

14. Vemer P, Corro Ramos I, van Voorn GAK, Al MJ, Feenstra TL. AdViSHE: a validation-assessment tool of health-economic models for decision makers and model users. Pharmacoeconomics. 2016;34(4):349-61. https://doi.org/10.1007/s40273-015-0327-2.

15. Royal Dutch Pharmacists Association (Koninklijke Nederlandse Maatschappij ter bevordering der Pharmacie). KNMP Nierfunctie. Knmp. 2014. Available at https://www.knmp.nl/downl oads/g-standaard/informatie-verminderde-nierfunctie.pdf/view. Accessed 17 Feb 2017.

16. Royal Dutch Pharmacists Association. Knowledge base (KNMP Kennisbank). Available at kennisbank.knmp.nl. Accessed 12 Dec 2017.

17. National Health Care Institute. Farmacotherapeutisch Kompas. Available at https://www.farmacotherapeutischkompas.nl/. Accessed July 9, 2018.

18. National Health Care Institute. Medicijnkosten. Available at https ://www.medicijnkosten.nl/. Accessed 3 May 2017.

19. Hakkaart-van Roijen L, Van der Linden N, Bouwmans CAM, Kanters TA, Tan SS. Costing manual: methodology of costing research and reference prices for economic evaluations in healthcare (Kostenhandleiding: methodologie van kostenonderzoek en referentieprijzen voor economische evaluaties in de gezondheidszorg). 2015.

20. Statistics Netherlands (Centraal Bureau voor de Statistiek) - Consumer price index, annual mutations. Available at statline.cbs.nl. Accessed 2 July 2018.

21. Service Apotheek. Available at https://www.serviceapotheek.nl/ service. Accessed July 6, 2018.

22. Menarini Diagnostics. Available at http://www.menarinidiagnos tics.nl/. Accessed July 6, 2018.

23. Foundation for Pharmaceutical Statistics (Stichting Farmaceutische Kengetallen). Overname leidt vooral tot minder formuleapotheken. Pharm Weekbl. 2017;152:9.

24. Geerts AFJ, De Koning FHP, De Vooght KMK, Egberts ACG, De Smet PAGM, van Solinge WW. Feasibility of point-of-care creatinine testing in community pharmacy to monitor drug therapy in ambulatory elderly patients. J Clin Pharm Ther. 2013;38(5):41622. https://doi.org/10.1111/jcpt.12081.

25. Leendertse AJ, van Dijk EA, De Smet PA, Egberts TC, van den Bemt PM. Contribution of renal impairment to potentially preventable medication-related hospital admissions. Ann Pharmacother. 2012;46(5):625-33. 